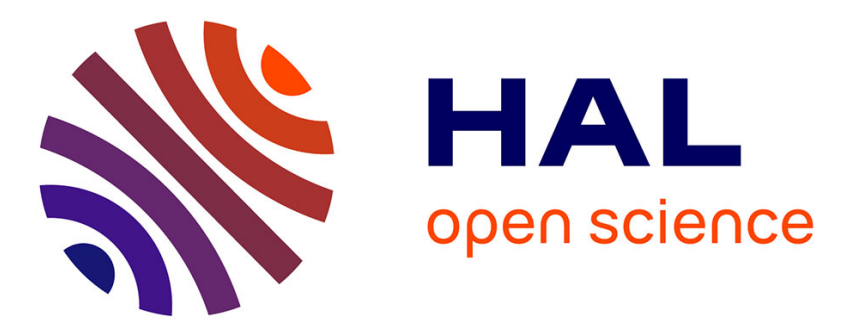

\title{
Temperature and emissivity extracted from airborne multi-channel data in the ReSeDA experiment
}

César Coll, Vicente Caselles, Eva Rubio, Enric Valor, Francisco Sospedra, Frédéric Baret, Laurent Prévot, Frédéric Jacob

\section{- To cite this version:}

César Coll, Vicente Caselles, Eva Rubio, Enric Valor, Francisco Sospedra, et al.. Temperature and emissivity extracted from airborne multi-channel data in the ReSeDA experiment. Agronomie, 2002, 22, pp.567 - 573. 10.1051/agro:2002034 . hal-03541121

\author{
HAL Id: hal-03541121 \\ https://hal.science/hal-03541121
}

Submitted on 24 Jan 2022

HAL is a multi-disciplinary open access archive for the deposit and dissemination of scientific research documents, whether they are published or not. The documents may come from teaching and research institutions in France or abroad, or from public or private research centers.
L'archive ouverte pluridisciplinaire HAL, est destinée au dépôt et à la diffusion de documents scientifiques de niveau recherche, publiés ou non, émanant des établissements d'enseignement et de recherche français ou étrangers, des laboratoires publics ou privés. 


\title{
Temperature and emissivity extracted from airborne multi-channel data in the ReSeDA experiment
}

\author{
César COLL ${ }^{\mathrm{a} *}$, Vicente CASELLES ${ }^{\mathrm{a}}$, Eva RUBIO ${ }^{\mathrm{a}}$, Enric VALOR ${ }^{\mathrm{a}}$, Francisco SOSPEDRA ${ }^{\mathrm{a}}$, Frédéric BARET ${ }^{\mathrm{b}}$, \\ Laurent PRÉVOT ${ }^{\mathrm{b}}$, Frédéric JACOB ${ }^{\mathrm{b}}$
}

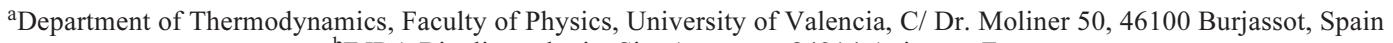

${ }^{\mathrm{b}}$ INRA Bioclimatologie, Site Agroparc, 84914 Avignon, France

(Received 13 November 2001; accepted 2 April 2002)

\begin{abstract}
Surface temperatures and emissivities were recovered from thermal infrared data of the Digital Airborne Imaging Spectrometer (DAIS) acquired over the ReSeDA site. Pre-processing of the DAIS thermal data included ground calibration using in situ measurements in two reference fields and atmospheric correction with nearby atmospheric radiosonde data. An adjusted normalised emissivity method was used, with the initial emissivity selected for each surface according to local measurements. Results were compared with ground measurements for several validation fields. The same comparison was made for the non-calibrated DAIS data. In all cases, the re-calibrated data yielded more reasonable results, showing the need for calibration measurements for the DAIS thermal channels. For the re-calibrated data, the retrieved temperatures were in good agreement with ground data. Some disagreement was found for the emissivities, with spectral variations not expected from the ground measurements. Such discrepancies could be due to errors still present in the re-calibration procedure and sensor stability.
\end{abstract}

temperature / emissivity / airborne data / ground measurements

Résumé - Estimation de la température et de l'émissivité à partir d'un capteur aéroporté pendant l'expérimentation ReSeDA. La température de surface et l'émissivité ont été estimées à partir des données infra-rouge thermiques du capteur DAIS (Digital Airborne Imaging Spectrometer) durant la campagne expérimentale ReSeDA. Le pré-traitement des données incluent l'étalonnage basé sur des mesures in situ dans deux parcelles de référence, et des corrections atmosphériques basées sur des sondages atmosphériques réalisés à proximité. Une méthode de normalisation de l'émissivité a été utilisée à partir de l'émissivité mesurée au sol sur différentes surfaces. Les résultats sont comparés à des mesures indépendantes réalisées sur les parcelles de validation. Ils montrent la nécessité du ré-étalonnage des données infra-rouge thermiques du capteur DAIS. Les températures estimées montrent un bon accord avec les mesures au sol. Toutefois, des écarts sont observés au niveau de l'estimation de l'émissivité, montrant des variations spectrales non attendues qui pourraient être dues à des erreurs résiduelles dans la procédure de ré-étalonnage et de stabilité de l'instrument.

température / émissivité / données aéroportés / mesures sol

\section{INTRODUCTION}

The recovery of LST and emissivity from thermal infrared remote sensing data is an underdetermined problem. Thermal radiances vary with both temperature and emissivity. Therefore, for $\mathrm{N}$ thermal spectral channels, there will be $\mathrm{N}+1$ unknowns: $\mathrm{N}$ emissivities (one per channel) and a single surface temperature. Separation of emissivity and temperature requires additional assumptions to break down the indeterminacy. Assumptions are often related to laboratory or field emissivity measurements. Previously, at-sensor radiances had to be corrected for atmospheric absorption and emission, mainly due to water vapour. The objective of this study is the derivation of an accurate data set of land surface temperature (LST) and emissivity in the framework of the ReSeDA project [6] from airborne thermal infrared measurements. The data set used in this work was collected in the ReSeDA test area during the intensive field campaign of July

Communicated by Thomas Schmugge (Beltsville, USA)

* Correspondence and reprints

cesar.coll@uv.es 
1997. It comprises thermal infrared data of the Digital Airborne Imaging Spectrometer (DAIS), and ground measurements of temperature and emissivity for a selection of fields.

The present study follows up the analysis presented in [2], where the quality of thermal images of the DAIS taken over the ReSeDA test site was checked with ground data. Important errors in the laboratory calibration of the DAIS were found, a problem identified in other DAIS data [3, 7, 12]. Calibration errors are inherent to the Kennedy scan mechanism used by DAIS, which means that the signal at the detector is contaminated by a considerable fraction of intrinsic background radiation. Calibration errors depend on the scene and cannot be predicted. In [2], a procedure was designed to re-calibrate the thermal channels of the DAIS with ground data in two reference fields. Unfortunately, the ground temperatures were biased due to calibration errors in the ground radiometers. In the present study, the corrected ground temperatures were used for a local re-calibration of DAIS data. With the new re-calibrated images, the adjusted emissivity normalisation method (ANEM, [3]) was applied to estimating surface temperature and channel emissivity over the ReSeDA test site. In this method, an initial emissivity value is selected for each surface type according to local emissivity measurements.

The present study presents first the experimental database, including laboratory emissivity measurements performed for several soil samples of the area. These measurements allow the characterisation of the spectral variation of soil emissivity within the area, and the correction of the ground temperatures. Next the pre-processing of DAIS thermal infrared is described, including the re-calibration and the atmospheric correction. Finally, the ANEM is applied to the two available flight lines of the DAIS and results are compared with ground data in terms of surface temperature and emissivity over validation fields.

\section{EXPERIMENTAL DATA SET}

The experimental data set comprises thermal infrared images of the DAIS from two flight lines over the ReSeDA test site, and ground measurements of emissivity and temperature in several fields used for calibration and validation. Figure 1 shows a map of the ReSeDA test site with some selected fields indicated. This area was flown by the DAIS on July 8 , 1997. The DAIS is a 79-channel high-resolution spectrometer covering the wavelength range between 0.5 and $13 \mu \mathrm{m}$, with 6 channels in the $8-13 \mu \mathrm{m}$ waveband region (channels 74-79). Details on the DAIS can be found in [5, 11]. DAIS data were provided in digital counts calibrated to at-sensor radiances (laboratory calibration). For the present study, we used DAIS flight lines 5 and 7 at 9: 42 and 10: 08 solar time, respectively.

During the intensive field campaigns of ReSeDA in April and July 1997, we performed emissivity measurements for the main crops and surfaces of the test area. The box method was used for the emissivity measurements. It uses a bottomless box with sides made of polished aluminium with reflectivity close to unity. Two interchangeable lids are used as the top of the box: the cold lid made of the same polished aluminium and the hot lid made of anodised, rough aluminium painted in Parson's black, with reflectivity close to zero. The hot lid was provided with an electrically powered heating system with a thermostat, which permits it to achieve stable,

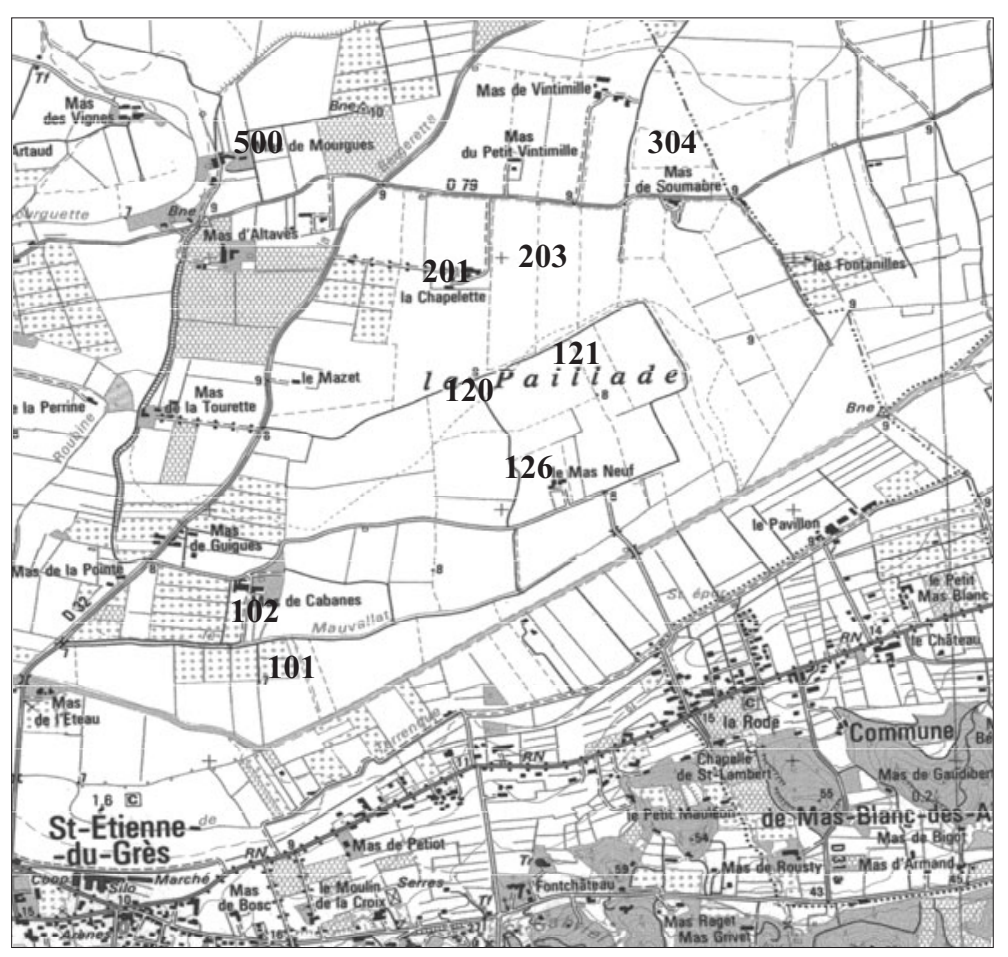

Figure 1. Map of the ReSeDA test area with some selected plots indicated. Fields 102, 121, 201 and 304 are sunflower crops with variable vegetation cover; fields 126 and 500 are corn crops with nearly full cover, field 203 is alfalfa with nearly full cover, and fields 101 and 120 are harvested wheat fields with certain amount of straw. 
Table I. Laboratory emissivity measurements in the CE 312 channels for soil samples from the indicated fields. The last column compares the field measurements obtained with the Everest radiometer.

\begin{tabular}{lccccc}
\hline & CE 312-ch. 4 & CE 312-ch. 3 & CE 312-ch. 2 & CE 312-ch. 1 & EVEREST-Field \\
\hline Field & $8.2-9.2 \mu \mathrm{m}$ & $10.5-11.5 \mu \mathrm{m}$ & $11.5-12.5 \mu \mathrm{m}$ & $8-13 \mu \mathrm{m}$ & $8-13 \mu \mathrm{m}$ \\
101 & $0.949 \pm 0.007$ & $0.962 \pm 0.003$ & $0.963 \pm 0.004$ & $0.961 \pm 0.004$ & $0.961 \pm 0.011$ \\
102 & $0.952 \pm 0.004$ & $0.967 \pm 0.003$ & $0.968 \pm 0.003$ & $0.968 \pm 0.002$ & $0.969 \pm 0.009$ \\
120 & $0.951 \pm 0.008$ & $0.963 \pm 0.004$ & $0.964 \pm 0.004$ & $0.965 \pm 0.002$ & $0.957 \pm 0.015$ \\
121 & $0.955 \pm 0.006$ & $0.967 \pm 0.003$ & $0.971 \pm 0.005$ & $0.967 \pm 0.003$ & $0.953 \pm 0.012$ \\
304 & $0.950 \pm 0.010$ & $0.962 \pm 0.006$ & $0.964 \pm 0.005$ & $0.963 \pm 0.003$ & $0.958 \pm 0.013$ \\
\hline
\end{tabular}

high temperatures $\left(\approx 55^{\circ} \mathrm{C}\right)$. The external sides and lids of the box were covered with a thermal insulator to assure a better temperature stability of the box-sample system. The box is placed over the sample and a series of radiometric measurements are made through small holes in the lids. For details on the box method, see [8].

With the box method, we performed field measurements for sunflower, alfalfa, maize and wheat fields, using an Everest radiometer $(8-13 \mu \mathrm{m})$. These measurements were designed to capture the spatial variability of emissivity in the area, and were published in [2]. We were also interested in the spectral variation of emissivity in the $8-13 \mu \mathrm{m}$ band. As a matter of fact, green vegetation is known to have a relatively flat spectrum, while soil emissivity may vary greatly with wavelength. For this reason, soil samples were collected from selected fields to perform laboratory spectral measurements. Soil samples were dry (so humidity could not change much from field to laboratory) and we intended to place the samples in the laboratory in the same conditions as observed in the field.

A four-band CIMEL thermal infrared radiometer (model CE 312, see [10] for details) was used in the laboratory. The CE 312 radiometer has a wide channel (channel 1, 8-13 $\mu \mathrm{m}$ ) and three narrow channels (channel 2, 11.5-12.5 $\mu \mathrm{m}$; channel 3, 10.5-11.5 $\mu \mathrm{m}$; and channel 4, 8.2-9.2 $\mu \mathrm{m}$ ). Thus, channel 1 is comparable to the Everest radiometers used in the field. The other three narrow channels permit an assessment of the spectral emissivity variations in the $8-13 \mu \mathrm{m}$ window.
Table I shows the emissivities measured for the soil samples in the four CE 312 channels. The last column of Table I shows the Everest field measurements for comparison. For each measurement, the standard error of estimate is given. Laboratory measurements were more accurate due to stable ambient conditions, which are not usually met in the field. Nevertheless, the agreement between laboratory and field measurements was satisfactory. The largest differences were found for fields 120 and 121, but they were comparable with the uncertainty of the field measurements. The narrow band measurements of Table I indicate a moderate spectral contrast $(\sim 0.015)$ with maximum emissivities in channel 2 and minimum emissivities in channel 4 . The emissivity values of Table I are very similar for the five different fields. From these results, we may expect small variability of soil emissivity in the ReSeDA area.

Additionally, we obtained spectral emissivity measurements for the same soils of Table I. Measurements were made in the laboratory with a Nicolet FTIR spectrophotometer with spectral resolution of $2 \mathrm{~cm}^{-1}$, approximately, and an integrating sphere (Hook, 1999, private communication; see http: //speclib.jpl.nasa.gov for details on the measurement protocol). Again, emissivity spectra were mostly similar for all soil samples. As an example, Figure 2 plots the spectra measured for field 121 compared with the laboratory CE 312 measurements.

As part of the ReSeDA experimental setup, surface temperatures were continuously measured with Everest thermal

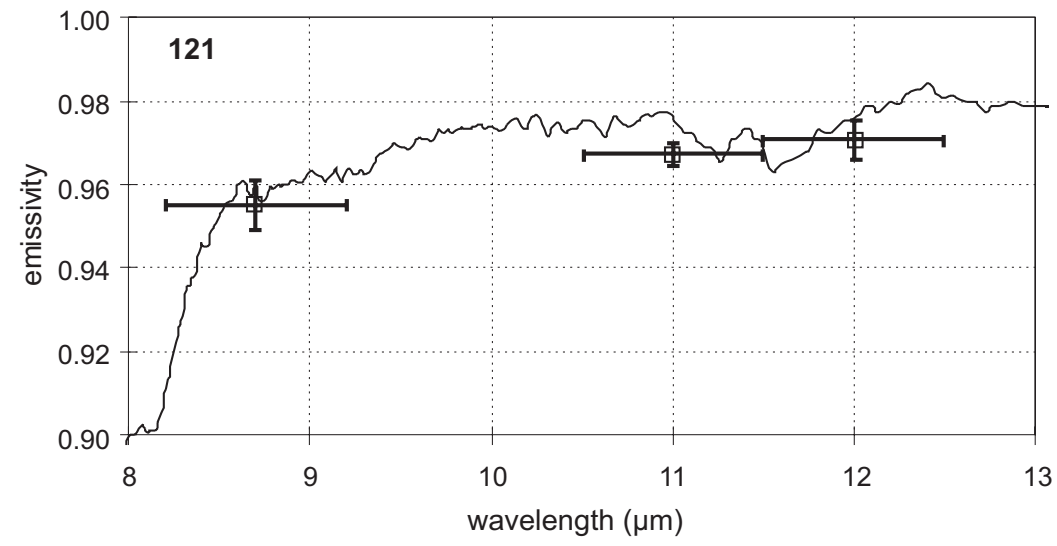

Figure 2. Soil emissivity spectra for field 121 (continuous line), and comparison with laboratory measurements for CE-312 channels 2-4 (thick error bars, the horizontal bar representing the bandwidth). 
Table II. Radiometric temperatures $\left(\mathrm{T}_{\mathrm{rad}}\right)$ and emissivity corrected temperatures (LST) measured at the indicated fields at the time of the DAIS flights.

\begin{tabular}{lcccc}
\cline { 2 - 5 } & \multicolumn{2}{c}{ Line $5-09: 42$} & \multicolumn{2}{c}{ Line $7-10: 08$} \\
\hline Field & $\mathrm{T}_{\text {rad }}\left({ }^{\circ} \mathrm{C}\right)$ & LST $\left({ }^{\circ} \mathrm{C}\right)$ & $\mathrm{T}_{\text {rad }}\left({ }^{\circ} \mathrm{C}\right)$ & LST $\left({ }^{\circ} \mathrm{C}\right)$ \\
203 & 24.1 & 24.7 & 25.2 & 25.8 \\
121 & 34.0 & 35.3 & 36.4 & 37.7 \\
\hline
\end{tabular}

infrared radiometers $(8-13 \mu \mathrm{m})$ at permanent stations located in some selected fields. Table II shows the temperature measurements for two fields at the time of the two DAIS flights used as calibration targets. In Table II, $\mathrm{T}_{\text {rad }}$ represents brightness or radiometric temperatures in the $8-13 \mu \mathrm{m}$ waveband. Emissivity effects (including the reflection of the sky radiance) were corrected using emissivity measurements for the corresponding sites, thus obtaining the ground LST given in Table II. For field 203 (alfalfa, full cover) the field measurement $\varepsilon=0.987$ from [2] was used. For field 121 (sunflower, partial cover) we used $\varepsilon=0.980$ as the effective emissivity calculated from the soil emissivity in CE 312 channel 1 (0.967; Tab. I), the vegetation emissivity $(0.985$ from field data in [2]) and estimations of the plant dimensions (see [2] for details on the effective emissivity calculation). The temperature data in Table II differ from those shown in Table IV of [2] due to errors in the initial calibration of the permanent ground radiometers. With these problems solved, an accuracy of $\pm 1{ }^{\circ} \mathrm{C}$ can be assigned to the temperatures of Table II.

\section{PRE-PROCESSING OF THERMAL INFRARED DAIS DATA}

The pre-processing of the thermal infrared DAIS data included two main steps: (1) re-calibration of the thermal channels, and (2) atmospheric correction of calibrated, at-sensor radiances to obtain the at-surface radiances.

The re-calibration of the DAIS thermal channels was carried out following the methodology described in $[2,3]$. Based on ground data, at-sensor radiances were calculated for two reference targets and compared to the DAIS original radiances extracted for the same sites. Fields 203 (alfalfa) and 121 (sunflower) were taken as cool and hot targets, respectively, with the temperatures of Table II. Emissivity estimates in the DAIS channels were also required. For field 203, a constant emissivity of 0.985 was assumed. For field 121 , the DAIS emissivities were calculated from the soil spectrum of Figure 2, and taking vegetation cover of $20 \%$ from field observations (see [2] for details).

In order to simulate the DAIS at-sensor radiances, the atmospheric transmittance and path radiance were required, as well as the downwelling sky flux (for the reflection term in the at-surface radiance). These atmospheric parameters were calculated using the MODTRAN radiative transfer model [1] with radiosonde atmospheric profiles measured in Nimes (30 km west of the site) by MétéoFrance at 12 solar time,
Table III. Coefficients for the linear re-calibration of DAIS thermal channels, equation (1). $\mathrm{N}_{\mathrm{j}}$ is in $\mathrm{mW} /\left(\mathrm{cm}^{2} \mathrm{sr} \mu \mathrm{m}\right)$.

\begin{tabular}{ccc}
\hline Channel & $\mathrm{G}_{\mathrm{j}}$ & $\mathrm{N}_{\mathrm{j}}$ \\
\hline 74 & 0.6818 & 0.2961 \\
75 & 0.7727 & 0.1650 \\
76 & 0.5374 & 0.3963 \\
77 & 0.7294 & 0.2065 \\
78 & 0.7542 & 0.1923 \\
79 & 0.6587 & 0.2933 \\
\hline
\end{tabular}

available through the ReSeDA database. Comparison of simulated and original DAIS at-sensor radiances showed the need for a re-calibration of the DAIS data ([2]). With the two targets, a linear re-calibration equation was derived, i.e.

$$
\mathrm{L}_{\mathrm{j}}^{\text {sens }}(\mathrm{rc})=\mathrm{G}_{\mathrm{j}} \times \mathrm{L}_{\mathrm{j}}^{\text {sens }}+\mathrm{N}_{\mathrm{j}}
$$

where $L^{\text {sens }}(\mathrm{rc})$ is the re-calibrated at-sensor radiance for DAIS channel $j, L^{\text {sens }}{ }_{j}$ is the original at-sensor radiance, and $G_{j}$ and $\mathrm{N}_{\mathrm{j}}$ are the re-calibration coefficients, which depend on the DAIS channel and flight line. They were calculated for DAIS flight line 5 and are listed in Table III. It was not possible to derive calibration coefficients for line 7 since this line did not cover the cold target (field 203). Therefore coefficients for line 5 were used for line 7 .

At-sensor, re-calibrated radiances were converted into at-surface radiances (i.e., the atmospheric correction) according to

$$
\mathrm{L}_{\mathrm{j}}^{\text {surf }}=\left[\mathrm{L}^{\text {sens }}{ }_{\mathrm{j}}(\mathrm{rc})-\mathrm{L}_{\mathrm{j}}^{\mathrm{atm}}(\theta)\right] / \tau_{\mathrm{j}}(\theta)
$$

where $\theta$ is the scan angle, $\mathrm{L}_{\mathrm{j}}^{\mathrm{atm}}$ is the atmospheric upwelling radiance and $\tau_{\mathrm{j}}$ is the atmospheric transmittance. The atmospheric parameters of equation (2) were calculated from the same radiosonde data as for the re-calibration.

It should be noted that the overall goal of equations (1) and (2) is to provide a linear relationship between original, at-sensor radiances and calibrated, at-surface radiances. This relationship is mainly determined by the ground data, its accuracy depending principally on their quality $\left( \pm 1^{\circ} \mathrm{C}\right.$ in temperature). Possible errors in the radiosonde data used for the atmospheric correction have a much smaller impact. In fact, they would cancel out for the most part since the same atmospheric parameters were applied first in the direct way (calculation of at-sensor radiances from ground data) and then in the reverse way (Eq. (2)). The atmospheric correction is necessary basically to take account of the angular effects in the at-sensor radiances, which are due to the increase in the atmospheric path with the scan angle ( $\pm 32^{\circ}$ for the DAIS). The Nimes radiosonde used here could be different from the actual profile due to the spatial and temporal variability of the atmosphere. However, it was close enough to correct accurately for angular effects in the at-sensor radiances. Assuming that the atmosphere did not change much between the two flights and did not vary throughout the area covered by the images, the Nimes radiosonde can be used with confidence for our purposes. 


\section{TEMPERATURE AND EMISSIVITY ESTIMATION}

The ground calibrated, at-surface radiances are related to the land surface temperatures, $\mathrm{T}$, and emissivity, $\varepsilon_{\mathrm{j}}$, through

$$
\mathrm{L}_{j}^{\text {surf }}=\varepsilon_{\mathrm{j}} \mathrm{B}_{\mathrm{j}}(\mathrm{T})+\left(1-\varepsilon_{\mathrm{j}}\right) \mathrm{L}^{\text {sky }}{ }_{\mathrm{j}}
$$

where $L^{\text {sky }}$ is the flux density of the downwelling atmospheric radiance divided by $\pi$, and $\mathrm{B}_{\mathrm{j}}$ is the Planck function weighted for the filter of channel $\mathrm{j}$. Equation (3) shows the coupling of LST and emissivity in $\mathrm{L}^{\text {surf }}$ ind also that of emissivity and sky radiance in the reflection term. In order to separate emissivity and LST, multispectral temperature-emissivity methods make an assumption in terms of emissivity or emissivity variation with wavelength, which is typically based on laboratory and field measurements. One of the simplest algorithms is the Normalised Emissivity Method (NEM [4]). It assumes a unique emissivity value, $\varepsilon_{\mathrm{NEM}}$, for all channels and all pixels. Then equation (3) can be solved for temperature for the $\mathrm{N}$ channels of the instrument as

$$
B_{j}\left(T_{\text {NEM } j}\right)=\frac{L_{j}^{\text {surf }}-\left(1-\varepsilon_{\text {NEM }}\right) L_{j}^{\text {sky }}}{\varepsilon_{\text {NEM }}}
$$

and $\mathrm{T}_{\mathrm{NEM}} \mathrm{j}$ is calculated through inversion of the averaged Planck function. Equation (4) provides a set of $\mathrm{N}$ values of temperature (one per channel) from which the maximum value is selected, $\mathrm{T}_{\max }=\max \left(\mathrm{T}_{\mathrm{NEMj}}\right)$. The maximum temperature is now used in equation (3) to solve for the $\mathrm{N}$ channel emissivities, that is,

$$
\varepsilon_{\mathrm{j}}=\frac{\mathrm{L}_{\mathrm{j}}^{\text {surf }}-\mathrm{L}_{\mathrm{j}}^{\text {sky }}}{\mathrm{B}_{\mathrm{j}}\left(\mathrm{T}_{\max }\right)-\mathrm{L}_{\mathrm{j}}^{\text {sky }}}
$$

$\mathrm{T}_{\max }$ and equation (5) provide a first estimate of surface temperature and emissivity, respectively. The accuracy of these estimates depends on the initial assumption of $\varepsilon_{\mathrm{NEM}}$. It can be easily seen that, for a given emissivity spectrum, the assumed $\varepsilon_{\text {NEM }}$ should be close to the maximum emissivity in the $\mathrm{N}$ channels of the sensor. Then, $\mathrm{T}_{\max }$ will occur at the channel with maximum emissivity and it will be close to the actual surface temperature. Thus, we have applied the NEM algorithm with adjusted $\varepsilon_{\text {NEM }}$ values, selected according to the nature of each surface.

The Adjusted NEM algorithm (ANEM, [3]) was adopted in the present work since actual values of maximum emissivities were available for different fields of the experimental area. Inspection of databases of spectral emissivity measurements (e.g., [9]) indicates that maximum emissivities take place in the $10.5-12.5 \mu \mathrm{m}$ window region for most natural surfaces. In addition, the variability of emissivity is small at these wavelengths, with values within the range 0.95-0.99. This fact allows us to choose an adequate value for the maximum emissivity. The ANEM approach used here combines the simplicity of the original NEM algorithm with the greater accuracy achieved by the use of field emissivity measurements.

Based on the spectral measurements, a maximum emissivity of 0.978 can be assigned for the ReSeDA soils, and of 0.985 for green vegetation. For mixed surfaces, the maximum emissivity can be calculated as [13]

$$
\varepsilon_{\mathrm{NEM}}=0.985 \mathrm{P}_{\mathrm{v}}+0.978\left(1-\mathrm{P}_{\mathrm{v}}\right)+4<\mathrm{d} \varepsilon_{\mathrm{i}}>\mathrm{P}_{\mathrm{v}}\left(1-\mathrm{P}_{\mathrm{v}}\right)
$$

where $\mathrm{P}_{\mathrm{v}}$ is the vegetation cover and $\left\langle\mathrm{d} \varepsilon_{\mathrm{i}}>\right.$ is a term accounting for the cavity effect, which is calculated from field observations of the plant dimensions and distribution [13]. $\mathrm{P}_{\mathrm{v}}$ was estimated through a vegetation index calculated from the reflective channels of the DAIS.

\section{RESULTS AND DISCUSSION}

The ANEM algorithm was applied to the re-calibrated, atmospherically corrected DAIS scenes. The input maximum emissivities, $\varepsilon_{\mathrm{NEM}}$, were calculated from equation (6). The results yielded $\varepsilon_{\text {NEM }} \approx 0.99$ for nearly full cover crops (e.g., alfalfa and corn) and for sunflower crops with vegetation cover as low as $20 \%$. Such high emissivity was due to cavity effects and the high value of soil emissivity. For wheat stubble fields (e.g., 120) equation (6) is not valid, and $\varepsilon_{\mathrm{NEM}}=0.96$ was selected according to the measurements of [2]. The value of $\mathrm{L}^{\mathrm{sky}}{ }_{\mathrm{j}}$ required for equations (4) and (5) was calculated from the atmospheric profiles and MODTRAN.

Recovered LSTs and channel emissivities are presented in this section for several selected fields. For each site, arrays of $5 \times 5$ pixels were extracted, from which the average and standard deviation of LST and emissivity were calculated. Figures 3 and 4 show the results for two fields in flight line 5. The average emissivity is plotted against the centre wavelength of the DAIS channels, the error bars representing one standard deviation. The derived LST is shown in the legend. For purposes of comparison, the results obtained with the original DAIS data (without ground re-calibration) are also shown. For each field, a reference emissivity spectrum is plotted for comparison. The reference emissivity was calculated from the soil spectra integrated in the DAIS channels and field measurements as detailed in [2].

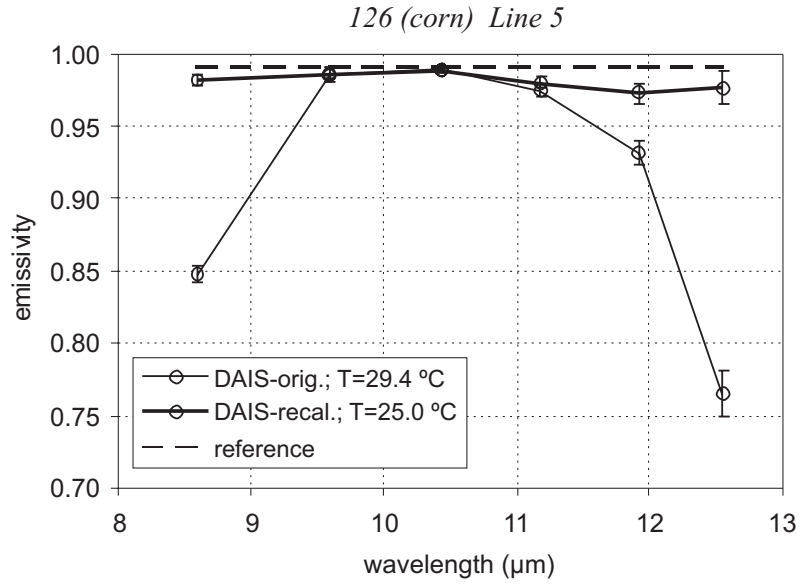

Figure 3. NEM emissivities obtained from re-calibrated DAIS data (bold line) and original DAIS data (continuous line) in field 126, line 5. The derived LSTs are shown in the legend. Reference spectra are plotted for comparison (dashed line). 
$120($ soil + stubble) Line 5

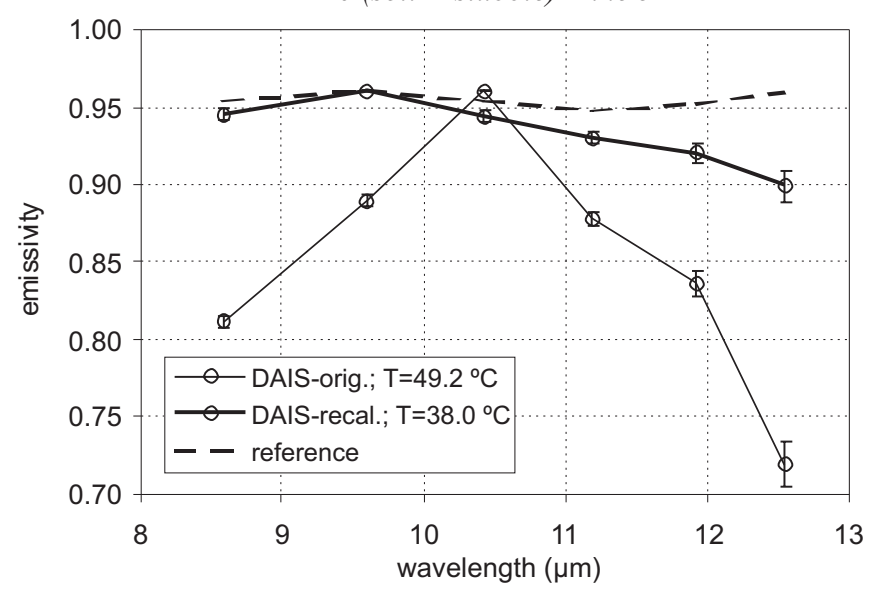

Figure 4. Same as Figure 3 except for field 120, line 5.

In all cases, the results obtained with the re-calibrated data were more reliable than those obtained with the original DAIS radiances. For the original data, the maximum channel temperature, $\mathrm{T}_{\max }$, was several degrees warmer than the expected surface temperatures and usually occurred for channel 76. Consequently, the retrieved emissivities in the other channels were largely underestimated. In Figure 3 (corn field 126 , full cover) the emissivity spectrum calculated from the re-calibrated data is in better agreement with the reference emissivity, with a mean difference of $+0.009 \pm 0.006$ for the six channels. Emissivities retrieved with the NEM are quite sensitive to the channel temperatures, $\mathrm{T}_{\mathrm{NEM}} \mathrm{j}$, from which the maximum temperature is selected. A difference $\mathrm{T}_{\max }-\mathrm{T}_{\mathrm{NEM} j}$ of $1{ }^{\circ} \mathrm{C}$ results in an emissivity difference of 0.02 . For field 126 , line 5 , the 6 channel temperatures were within $0.9{ }^{\circ} \mathrm{C}$. This figure is close to the accuracy of the ground temperatures used for the re-calibration $\left( \pm 1^{\circ} \mathrm{C}\right)$. Although no temperature measurements were available for field 126, the derived LST was close to the temperature measured for the full cover alfalfa field $203\left(24.7^{\circ} \mathrm{C}\right.$, Tab. II). Results for other fully vegetated crops (e.g., sunflower fields 201 and 304 , and corn field 500, not shown) were similar. Air temperature at a nearby meteorological station was $24-25^{\circ} \mathrm{C}$ at the time of the DAIS flights.

For field 120, line 5 (wheat stubble, Fig. 4), the retrieved emissivity shows larger discrepancies (up to 0.06 for channel 79) compared with the expected values. The retrieved LST was comparable to the measurement for field 121 $\left(35.3{ }^{\circ} \mathrm{C}\right.$, Tab. II). Errors in the retrieved emissivities could be due to uncertainties in the re-calibration, which were particularly greater for the hot target used in this work. Our hot target (field 121) had a certain amount of vegetation so its LST was not the maximum of the temperature range. For the same reason it was not as uniform as the cold target (field 203), as revealed by the higher variability observed in the DAIS data (standard deviation of $1.5^{\circ} \mathrm{C}$ and $0.3{ }^{\circ} \mathrm{C}$ for fields 121 and 203, respectively). Additionally, it is more difficult to make ground LST measurements in such a field comparable with the airborne measurements.
The results obtained for flight line 7 are shown in Figures 5-7. The re-calibration of DAIS line 7 was done with the coefficients derived for line 5 (Tab. III). For Figures 5 and 6, the data extraction was done for the same spot as for Figures 3 and 4, respectively. In terms of emissivity, we found large differences between the two lines. These discrepancies were also observed in the original DAIS data, where the emissivities derived in channels 78 and 79 were much higher for line 7 than for line 5. When the re-calibration equations derived for line 5 were applied to line 7 , the maximum temperatures were always obtained for channel 79. Thus the assumed $\varepsilon_{\text {NEM }}$ was recovered in this channel, the other channels yielding lower emissivities. Although some improvement was obtained compared with results for the original DAIS data, it appears that line 7 required an independent calibration. Results were more reliable in terms of temperature since the derived LSTs were a few degrees higher for line 7 (according to Tab. II, surface temperatures were expected to

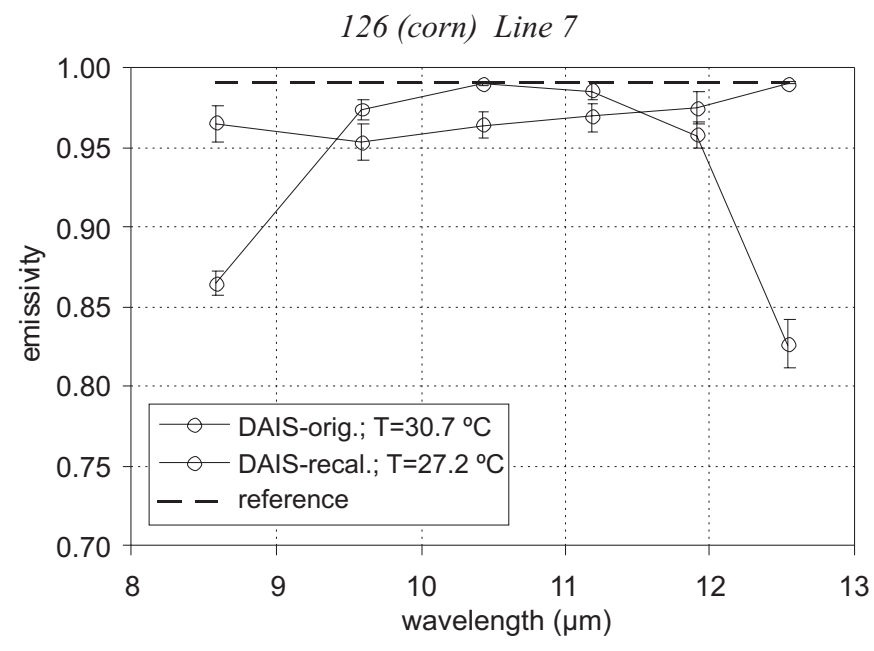

Figure 5. Same as Figure 3 except for field 126, line 7.

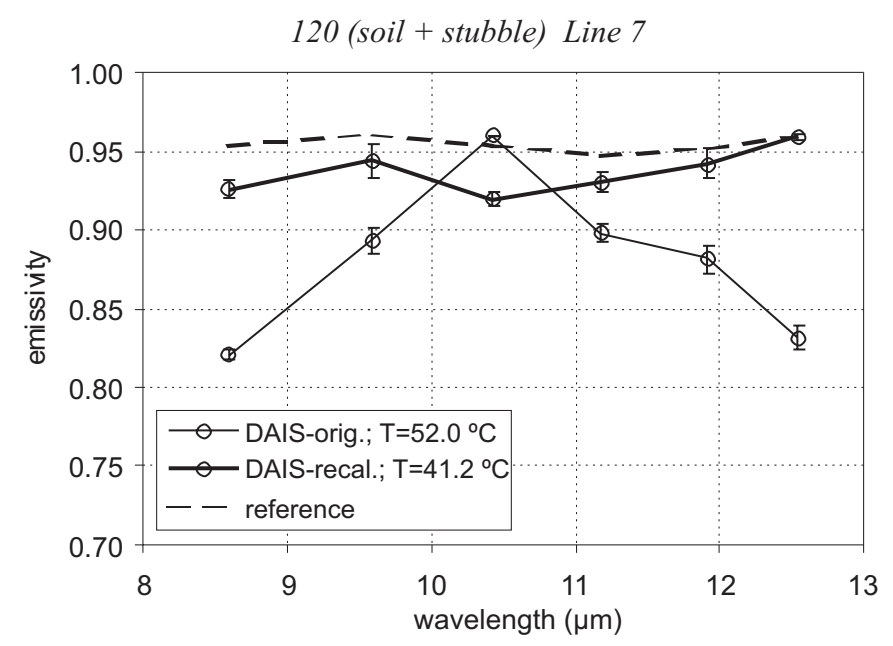

Figure 6. Same as Figure 3 except for field 120, line 7. 
121 (sunflower) Line 7

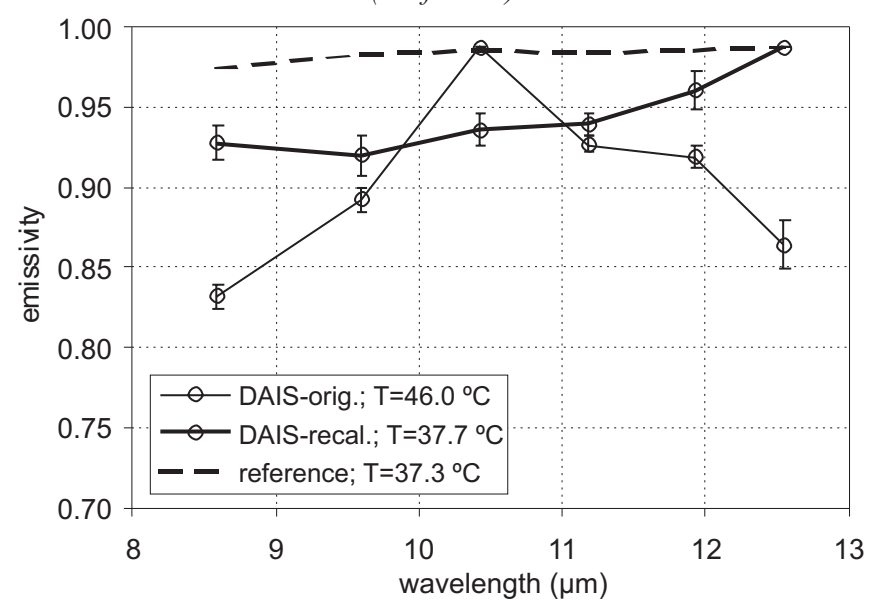

Figure 7. Same as Figure 3 except for field 121, line 7. The ground measurement of LST is given in the legend.

increase by $1-3{ }^{\circ} \mathrm{C}$ from line 5 to line 7 ). Finally, Figure 7 shows the results for field 121 , line 7 . In this case, the ground temperature of Table II is available for validation since it was not used for calibration. The resulting emissivity is only good for channel 79 (where $\mathrm{T}_{\max }$ is obtained), with the other channels yielding underestimated values. However, the recovered LST is only $0.4{ }^{\circ} \mathrm{C}$ higher than the measured value.

\section{CONCLUSION}

LST and emissivity were recovered from DAIS thermal data using an adjusted normalised emissivity method (ANEM) in which the initial maximum emissivity, $\varepsilon_{\text {NEM }}$, was selected for each surface type from available emissivity measurements. Previously, the thermal channels of DAIS were re-calibrated using ground measurements in two reference fields, and the atmospheric correction was performed using a nearby radiosonde and the MODTRAN radiative transfer code. With the re-calibrated, atmospherically corrected radiances, the ANEM was applied and recovered temperatures and channel emissivities were analysed for fields other than those used for the re-calibration. Besides, temperature and emissivity were retrieved for the original DAIS data, i.e., without the ground calibration. In all cases, the re-calibrated data yielded better results than the original data, in terms of both LST and emissivities. However, some discrepancies in the retrieved emissivities still remained, which could be attributable to errors in the re-calibration procedure. This was more evident for the results of line 7 , which were re-calibrated with the coefficient set derived for line 5. It is therefore recommended to use a particular set of re-calibration coefficients for each line. On the other hand, the recovered surface temperatures were in the range of the ground measurements. Particularly, for field 121, line 7 (not used for re-calibration), the derived temperature was $37.7^{\circ} \mathrm{C}$ whereas the measured value was $37.3^{\circ} \mathrm{C}$. This gives confidence in the LSTs estimated from the re-calibrated DAIS data.

Acknowledgements: The present work has been financed by the Spanish CICyT (contract AMB96-1928-CE) and the European Union through the ReSeDA project (contract ENV4-CT960326-PL952071). The Conselleria de Cultura, Educació $i$ Ciència, Generalitat Valenciana, is acknowledged for additional financial support. We wish to thank Dr. S. Hook (Jet Propulsion laboratory) for the spectral emissivity measurements.

\section{REFERENCES}

[1] Berk A., Bernstein L.S., Robertson D.C., MODTRAN: A Moderate Resolution Model for LOWTRAN 7, Tech. Rep. GL-TR-89-0122, Geophys. Lab., Bedford Mass., 1989.

[2] Coll C., Caselles V., Rubio E., Sospedra F., Valor E., Analysis of thermal infrared data from the Digital Airborne Imaging Spectrometer, Int. J. Remote Sens. 22 (2001) 3703-3718.

[3] Coll C., Caselles V., Rubio E., Sospedra F., Valor E., Temperature and emissivity separation from calibrated data of the Digital Airborne Imaging Spectrometer, Remote Sens. Environ. 76 (2001) 250-259.

[4] Gillespie A., Lithologic mapping of silicate rocks using TIMS, Proc. TIMS Data User's Workshop, JPL Publ. 83-38 (1986) 29-44.

[5] Müller A., Oertel D., Richter R., Strobl P., Beran D., Fries J., Boehl R., Obermeier P., Hausold A., Reinhaeckel G., The DAIS 7915-Three years operating airborne imaging spectrometer, Proc. 1st EARSel Workshop on Imaging Spectrometry, EARSeL, Paris (1998), pp. 21-28.

[6] Prévot L., Baret F., Chanzy A. et al., Assimilation of Multi-sensor and Multi-temporal Remote Sensing Data to Monitor Vegetation and Soil: the Alpilles-ReSeDA project, IGARSS'98, Int. Geosci. Remote Sens. Symp., Seattle, WA, USA, (IEEE: Piscataway), 1998, pp. 2399-2401.

[7] Richter R., Coll C., Caselles V., Rubio E., Valor E., Vicarious calibration and validation in the thermal region, SPIE Proc. 4538 (2001) (in press).

[8] Rubio E., Caselles V., Badenas C., Emisivity measurements of several soils and vegetation types in the $8-14 \mu \mathrm{m}$ wave band: Analysis of two field methods, Remote Sens. Environ. 59 (1997) 490-521.

[9] Salisbury J.W., D'Aria D.M., Emissivity of terrestrial materials in the 8-14 $\mu \mathrm{m}$ atmospheric window, Remote Sens. Environ. 42 (1992) 83-106.

[10] Sicard M., Spyak P.R., Brogniez G., Legrand M., Abuhassan N.K., Pietras C., Buis J.-P., Thermal-infrared field radiometer for vicariuos cross-calibration: characterization and comparison with other field instruments, Opt. Eng. 38 (1999) 345-356.

[11] Strobl P., Müller A., Schläpfer D., Schaepman M., Laboratory calibration and in-flight validation of the Digital Airborne Imaging Spectrometer DAIS 7915, SPIE Proc. 3071 (1997) 225-235.

[12] Strobl P., Zhukov B., Recent developments in the 3-12 $\mu$ m radiometric calibration of the DAIS 7915, Proc. 1st EARSeL Workshop on Imaging Spectroscopy, EARSeL, Paris (1998), pp. 69-79.

[13] Valor E., Caselles V., Mapping land surface emissivity from NDVI: Application to European, African and South American areas, Remote Sens. Environ. 57 (1996) 167-184. 